\title{
A rare case of distant metastasis of primary malign pericardial mesothelioma with 18F-FDG PET/CT
}

\author{
Tarik Sengoz $^{1 *}$, Nilufer Avci ${ }^{2}$, Ezgi Basak Erdogan ${ }^{3}$, Erdogan Bulbul ${ }^{4}$ \\ ${ }^{1}$ Dept. of Nuclear Medicine, Pamukkale University, Faculty of Medicine, Denizli , Turkey \\ ${ }^{2}$ Dept. of Medical Oncology, Medicana Hospital, Bursa, Turkey \\ ${ }^{3}$ Dept. of Nuclear Medicine, Bezmialem Vakif University, Faculty of Medicine, İstanbul ,Turkey \\ ${ }^{4}$ Dept. of Radiology , Balikesir University, Faculty of Medicine, Balikesir , Turkey
}

${ }^{*}$ Corresponding to: Tarik Sengoz, Dept. of Nuclear Medicine, Pamukkale University, Faculty of Medicine, Denizli , Turkey; Email: tsengoz@pau.edu.tr

Received: June 10, 2019; Accepted: June 19, 2019; Published: July 09, 2019;

\begin{abstract}
Primary pericardial mesothelioma is a rare malignant tumor derived from the pericardial mesothelial cell layers. 65-year-old man was admitted to hospital with dyspnea and chest pain. Pericardial effusion and pericardial tamponade were observed with transthoracic echocardiography. Contrastenhanced computed tomography (CECT) demostrated pericardial effusion, diffuse pericardial thickening and pleural effusion in both hemithorax. The final diagnosis was proven as primary malignant pericardial mesothelioma with histopathological evaluation. Subsequently, F-18 FDG PET-CT scan demonstrated high FDG uptake in pericardial thickening areas. Additionally, increased FDG uptake was also seen in the hypodense lesions in the both adrenal gland lesions and in liver.
\end{abstract}

Keywords: PET-CT, echocardiography, primary malign pericardial mesothelioma, FDG

\section{INTRODUCTION}

Malignant mesothelioma (MPM) is a rare, aggressive malignant tumor derived from the mesothelial cells of serosal membranes. Malignant mesothelioma may occur most frequently from the pleura (90\%), less frequently from the peritoneum $(6-10 \%)$ and from the pericardium, and very rarely from the tunica vaginalis in the testis [1]. Primary pericardial mesotheliomas (PPM) very rare malignancy (incidence $0,0022 \%$ ). It represents $6 \%$ of all mesothelioma cases [2]. It usually provides nonspecific findings such as dyspnea, fever, cough and chest pain. It is more common in men. The mean age was 46 (19-76) years [3]. Mesotheliomas particularly metastasize to the intratorasic lymph nodes or lung, distant extrathorasic metastasis is very rarely observed [4]. Various imaging methods can be used for the diagnosis such as echocardiography (ECO), chest X-ray, chest $\mathrm{CT}$, magnetic resonance imaging (MRI) and positron emission tomography-computed tomography (PET-CT) [5]. PET-CT imaging have an important role in staging, treatment response, recurrence detection and prognosis in pleural mesothelioma [6]. In contrast to pleural mesothelioma, a few case reports with PPM is described by FDG PET-CT [7].

\section{CASE}

A 65-year-old male was admitted to the cardiology clinic with complaints of dyspnea and chest pain. He had no prior history of exposure to asbestos. Echocardiography showed pericardial effusion and tamponade findings. Diagnostic and therapeutic pericardiocentesis with pericardial drain was performed, all laboratory analyses showed normal results, cultivations and polymerasechain reaction (PCR) for tuberculosis were negative. Contrast-enhanced computed tomography (CECT) showed pericardial effusion, diffuse pericardial thickening and pleural effusion in both hemithorax (Figure 1-F).

F-18 FDG PET-CT scan demostrated intense uptake in diffuse pericardial thickening areas, with a maximum standardized uptake value (SUVmax) of 6.2 (Figure 1-A). Fused PET-CT images indicated the thickened pericardium with high FDG uptake (Figure 1-B,C). Furthermore, fused PET-CT images showed increased FDG uptake both in adrenal gland lesions (SUVmax: 3.1-5.8) (Figure 1-D) and in the hypodense lesion with a diameter of $1 \mathrm{~cm}$ in in liver segment 4A (SUVmax: 4.0) (Figure 1-E). Cytologic evaluation of pericardial effusion demonstrated with malignant pericardial mesothelioma. However, immunohistochemistry evaluation was not able to be performed. The case was evaluated as the PPM with liver and bilateral surrenal gland metastases. While the chemotherapy was planning, the patient had multiorgan insufficiency and emergency dialysis. Cardiac arrest developed two times during the dialysis and resulted in death.

\section{DISCUSSION}

PPM is a very rare malignant tumor of $6 \%$ of all mesotheliomas [8]. It can be seen in the form of mass formation or disseminated pericardial thickening. The effect of asbestos exposure is not as clear as pleural and peritoneal mesothelioma. The symptoms are usually nonspecific (fatigue, shortness of breath, chest pain, cough, etc.). It may indicate pericardial effusion, constrictive pericarditis, cardiac tamponade, and congestive heart failure in the clinic [9]. Imaging 
methods such as chest radiography, transthoracic echocardiography, CECT, MRI are used in the diagnosis.

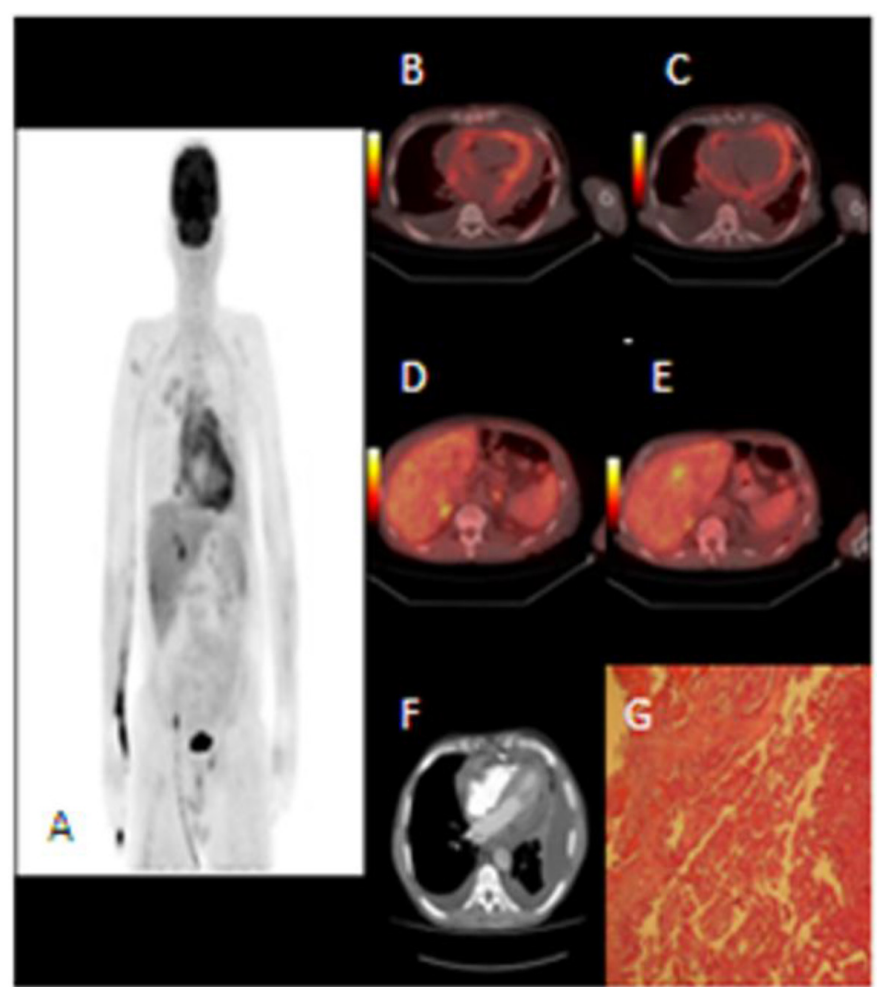

Figure 1. A-MIP imaging of PET. B.C.D.E- Axial fusion imaging. B.C-Diffuse FDG uptake in pericardial thickining (SUVmax: 6,2). D- Focal FDG uptake in both adrenal glands (SUVinax: 3,1 and 5,8). E-Focal FDG uptake in liver (SUVmax: 4,0). F-Axial CECT show diffuse pericardial thickining and effusion. G-liistopathological evaluation of malignant pericardial mesotheliomas (H\&E).
In ECO and chest X-ray radiography, an enlarged heart silhouette and pericardial effusion are described, whereas the pericardial mass cannot be differentiated. In a review of 28 pericardial mesothelioma cases, mediastinel mass could be differentiated in only one of 24 cases with X-ray graph [3]. Although CECT is an effective examination to demonstrate tumor invasion and pericardial thickening, sometimes large pericardial effusion complicate the evaluation of the mass [10]. ECO and CECT have a low sensitivity (12-44\%) in detecting pericardial mass (3). The use of MRI is limited, high signal intensity in T2-weighted image has been demonstrated in one patient [11].

FDG is a glucose analogue and offers metabolic information on the basis of increased glucose uptake due to the increased glucose requirement in cancer cells. PET-CT is frequently used in the diagnosis, staging and treatment response of many different cancers. Since the use of PET-CT in pleural mesothelioma has been well known [6], the knowledge in PPM is limited. There was no information about FDG PET-CT in the review of Thomson et al. with 27 PPM cases between 1972-1992 [3] and in the review of Nilsson et al. with 29 PPM cases between 1994-2008 [12]. After 2008, 5 PPM cases confirmed with PET-CT were found [13-17] . 3 of 5 cases were female and 2 of them were male. The average age is 52 (19-72). The characteristics of 5 cases are summarized in Table 1. In 3 of the patients, PET-CT showed no regional lymph nodes and distant metastases, while the other 2 cases had mediastinel lymph node metastasis $[15,17]$. In our case, liver and bilateral surrenal gland metastasis were detected. Thus, our case was the first case with liver and adrenal metastasis detected by PET-CT. Metastasis is seen in $25-45 \%$ of PPM cases. Generally, regional lymph nodes, lung and kidney metastases were detected [18]. Nilsson et al. study, metastasis was defined in 16 (55\%) of 29 PPM cases (lymph

Table 1. Cases of pericardial mesothelioma with F-18 FDG PET/CT published in the literature

\begin{tabular}{|c|c|c|c|c|c|c|c|}
\hline Case & Age & Sex & Symptom & $\begin{array}{l}\text { Asbestos } \\
\text { exposure }\end{array}$ & Radiological imaging & PET-CT & Pathology \\
\hline $\begin{array}{l}\text { Our } \\
\text { case }\end{array}$ & 65 & M & $\begin{array}{l}\text { Dyspnea, chest } \\
\text { pain }\end{array}$ & none & $\begin{array}{l}\text { USG: pericardial effusion } \\
\text { CT: pericardial effusion, } \\
\text { pericardial thickining }\end{array}$ & $\begin{array}{l}\text { PPM (SUVmax:6.2), liver } \\
\text { (SUVmax:4.0) and bilateral adrenal } \\
\text { (SUVmax:3.1-5.8) met }\end{array}$ & pericardiosentesis \\
\hline 3 & 72 & F & unspecified & none & CT: pericardial thickining & PPM (SUVmax not specified) & pericardial biopsy \\
\hline 4 & 58 & F & Fewer, fatigue & unspecified & $\begin{array}{l}\text { X-ray: enlarged cardiac silhouette } \\
\text { USG: pericardial effusion without } \\
\text { ventricul dilatation } \\
\text { CT: pericardial mass }\end{array}$ & $\begin{array}{l}\text { PPM (SUVmax:12.9) and dissemine } \\
\text { pericardial spread }\end{array}$ & Subtotal pericardiectomy \\
\hline 5 & 19 & F & $\begin{array}{l}\text { Dyspnea, chest } \\
\text { pain, low exercise } \\
\text { capacity }\end{array}$ & unspecified & $\begin{array}{l}\text { X-ray: enlarged cardiac silhouette } \\
\text { USG: pericardial effusion without } \\
\text { ventricul dilatation } \\
\text { CT: pericardial thickining/effusion } \\
\text { MR: pericardial mass }\end{array}$ & $\begin{array}{l}\text { PPM (SUVmax:5.22) and mediastinel } \\
\text { lymph node metastasis (SUVmax:1.6) }\end{array}$ & Partial pericardiectomy \\
\hline 7 & 54 & M & Dyspnea & none & $\begin{array}{l}\text { USG: pericardial effusion without } \\
\text { ventricul dilatation } \\
\text { CT: pericardial thickining/effusion }\end{array}$ & PPM (SUVmax:7.5) & pericardiectomy \\
\hline 8 & 57 & M & $\begin{array}{l}\text { Dyspnea, ankle } \\
\text { edema }\end{array}$ & unspecified & USG: constrictive pericarditis & $\begin{array}{l}\text { PPM (SUVmax:19.5) and mediastinel } \\
\text { lymph node metastasis }\end{array}$ & pericardiectomy \\
\hline
\end{tabular}

M: male, F:female, USG: transthoracic echocardiography, CT: Computed tomography, MR: Magnetic resonance imaging, PET-CT: positron emission tomography- computed tomography, PPM: primary pericardial mesothelioma 
nodes, liver and lung metastasis) [12]. Cytological examination of pericardial fluid in PPM does not always distinguish between reactive / malignant cells. Pericardial biopsy may be required for the final diagnosis [19]. Although the diagnosis was made after pericardiectomy in 5 cases in literature, our patient was diagnosed with pericardiocentesis (Table 1).

Treatment is often palliative, curative treatment is not possible in PPM. Surgical resection, chemotherapy and radiotherapy are the treatment options. Average survival was reported as 10 months in one study [19]. Our patient was died 16 day after the diagnosis.

Consequently, PET-CT can change the management of patients with PPM by showing the distant metastasis. However, the shortness of survival and the palliative treatment are the factors that limit the effect of PET-CT on the treatment plan. Our case is differentiated due to liver and bilateral surrenal metastasis from PPM confirmed by PET-CT in the literature. In the future, it can be predicted that PETCT have an important role for PPM like pleural mesothelioma.

\section{REFERENCES}

1. Adams VI, Unni KK, Muhm JR, et al. (1986) Diffuse malignant mesothelioma of pleura: Diagnosis and survival in 92 cases. Cancer 58: 1540-51. [Crossref]

2. Ohmori T, Arita N, Okada K, et al. (1995) Pericardial malignant mesothelioma: case report and discussion of immunohistochemical and histological findings. Pathol Int. 45: 622-625. [Crossref]

3. Thomason R, Schlegel W, Lucca M, et al (1994) Primary malignant mesothelioma of the pericardium. Case report and literature review. Tex Heart Inst J 21: 170-174. [Crossref]

4. Silvestri F, Bussani R, Pavletic N, et al. (1997) Metastases of the hearth and pericardium. G Ital Cardiol. 27: 1252-1255.

5. Maisch B, Seferovic PM, Ristic AD, et al. (2004) Guidelines on diagnosis and management of pericardial diseases executive summary; The task force on the diagnosis and management of pericardial diseases of the European society of cardiology. Eur Hearth J. 25: 587-610. [Crossref]

6. Gerbaudo VH, Sugarbaker DJ, Britz-Cunningham S, et al. (2002) Assessment of malignant pleuralmesothelioma with (18)F-FDG dual-head gamma-camera coincidence imaging: comparison with histopathology. J Nucl Med. 9: 1144-1149. [Crossref]

7. Ceresoli GL, Chiti A, Zucali PA, et al. (2006) Early response evaluation in malignant pleural mesothelioma by positron emission tomography with $[18 \mathrm{~F}]$ fluorodeoxyglucose. J Clin Oncol. 24: 4587-4593. [Crossref]

8. Burke A, Virmani R (1996) Malignant mesothelioma of the pericardium. In: Rosai J, Sobin LH, eds. Tumors of the Heart and Great Vessels. Atlas of Tumor Pathology, Third Series, Fascicle 16. Washington, DC: Armed Forces Institute of pathology; 181-194.

9. Eren NT, Akar AR. (2002) Primary pericardial mesothelioma. Curr Treat Options Oncol 3: 369-73. [Crossref]

10. Quinn DW, Qureshi F, Mitchel IM. (2000) Pericardial mesothelioma: the diagnostic dilemma of misleading images. Ann Thorac Surg. 69: 1926-1927.

11. Gössinger HD, Siostrzonek P, Zangeneh M, et al. (1988) Magnetic resonance imaging findings in a patient with pericardial mesothelioma. Am Heart $J 115$ : 1321-2. [Crossref]

12. Nilsson A, Rasmuson T. (2009) Primary pericardial mesothelioma: Report of a patient and literature review. Case Rep Oncol 2: 125-132. [Crossref]

13. Sakuraba M, Tatsumori T, Hirama M, Ogura K.(2011) Malignant pericardial mesothelioma. European Journal of Cardio-thorasic Surgery 39: 420.

14. Aga F, Yamamoto Y, Norikane T, Nishiyama Y. (2012) A case of primary pericardial mesothelioma detected by ${ }^{18} \mathrm{~F}-\mathrm{FDG}$ PET/CT. Clin Nucl Med 37: 522-523. [Crossref]

15. Ost P, Rottey S, Smeets P, et al. (2008) F-18 Fluorodeoxyglucose PET/CT scanning in the diagnostic work-up of a primary pericardial mesothelioma: a case report. $J$ Thorac Imaging 23: 35-38. [Crossref]

16. Sivrikoz İA, Onner H, Dundar EK, et al. (2016) F-18 FDG PET/CT images of rare primer cardiac tumour: primary pericardial mesothelioma. Anatol J Cardiol 16: 635-638. [Crossref]

17. Edel JP, Balink H. (2018) ${ }^{18} \mathrm{~F}-\mathrm{FDG}$ PET/CT revealing constrictive pericarditis as the only manifestation of malignant mesothelioma. Clin Nucl Med 00: 00 (accepted, but yet unpublished). [Crossref]
18. Karadzic R, Kostic-Banovic L, Antovic A, et al. (2005) Primary pericardial mesothelioma presenting as constrictive pericarditis. Arch Oncol 13: 150-152.

19. Kaul TK, Fields BJ, Kahn DR. (1994) Primary malignant pericardial mesothelioma: a case report and review. J Cardiovasc Surg. 35: 261-267. [Crossref]

\section{Citation:}

Tarik Sengoz, Nilufer Avci, Ezgi Basak Erdogan, Erdogan Bulbul (2019) A rare case of distant metastasis of primary malign pericardial mesothelioma with 18F-FDG PET/CT. J Clin Res Med Volume 2(3): 1-3. 